\title{
Disruption of rhythms of molecular clocks in primary synovial fibroblasts of patients with osteoarthritis and rheumatoid arthritis, role of IL- $1 \beta / \mathrm{TNF}$
}

Stefanie Haas and Rainer H Straub*

\begin{abstract}
Introduction: Circadian rhythms play an important role in the body and in single cells. Rhythms of molecular clocks have not been investigated in synovial fibroblasts (SF) of patients with osteoarthritis (OA) and rheumatoid arthritis (RA). The study was initiated to fill this gap and to study effects of interleukin (IL)-1ß/tumor necrosis factor (TNF) on rhythmicity in synovial fibroblasts of RA and OA patients.
\end{abstract}

Methods: The presence of BMAL-1, CLOCK, Period 1 and Period 2 proteins in synovial tissue was investigated by immunofluorescence. The presence of mRNA of molecular clocks was studied during $72 \mathrm{~h}$ by qPCR. Characteristics of rhythms were studied with time series analysis.

Results: BMAL-1, CLOCK, Period 1 and Period 2 proteins were abundantly present in synovial tissue of OA, RA and controls. Receiving synovial tissue at different operation time points during the day (8:00 am to 4:00 pm) did not reveal a rhythm of BMAL-1 or Period 1 protein. In OASF and RASF, no typical rhythm curve of molecular clock mRNA was observed. Time series analysis identified a first peak between 2 and 18 hours after synchronization but a period was not detectable due to loss of rhythm. TNF inhibited mRNA of CLOCK, Period 1 and Period 2 in OASF, while IL-1 $\beta$ and TNF increased these factors in RASF. This was supported by dosedependently increased levels in MH7A RA fibroblasts. In RASF, IL-1 $\beta$ and TNF shifted the first peak of BMAL-1 mRNA to later time points ( $8 \mathrm{~h}$ to $14 \mathrm{~h}$ ).

Conclusion: Rhythmicity is not present in primary OASF and RASF, which is unexpected because fibroblasts usually demonstrate perfect rhythms during several days. This might lead to uncoupling of important cellular pathways.

\section{Introduction}

Symptoms, such as swelling, pain, stiffness, and functional ability, follow a circadian rhythm in patients with rheumatoid arthritis (RA) [1]. The circadian change of symptoms depends on increased levels of proinflammatory cytokines in the late night and early morning [1-4], which can be blocked by night time application of glucocorticoids [4-6]. Circadian changes on the level of the entire body might be translated into rhythmic phenomena in peripheral cells of inflamed tissue. While

\footnotetext{
* Correspondence: rainer.straub@klinik.uni-regensburg.de Laboratory of Experimental Rheumatology and NeuroendocrinoImmunology, Division of Rheumatology, Department of Internal Medicine I, University Hospital, F. J. Strauss-Allee 11, Regensburg, 93053, Germany
}

oscillations of the entire system are dependent on external synchronizers, such as light, and are called circadian rhythms, undulations of intracellular molecular clock networks are dubbed daily rhythms depending on synchronization with, for example, serum shock. These intracellular daily rhythms have never been investigated in primary material of patients with RA and osteoarthritis $(\mathrm{OA})$.

The circadian rhythm is generated in the superordinate hypothalamic nucleus suprachiasmaticus [7], and this rhythm can be transferred to peripheral cells of the body by hormonal and neuronal signals [8-12]. Under physiological conditions, this was described for hepatocytes, cardiomyocytes, peripheral blood
C Biomed Central 
mononuclear cells, natural killer cells, CD4+ T cells and others [8-13]. After synchronization with serum shock in vitro, rhythms of molecular clocks are often self-sustained under constant culture conditions $[12,14,15]$. This has been demonstrated for neurons of the nucleus suprachiasmaticus [14], T cells [12] and fibroblasts [15]. Particularly, fibroblasts demonstrated a self-sustained rhythm with three regular periods and stable amplitudes over 72 hours [15]. This peripheral rhythm of fibroblasts can be modulated by systemic factors, such as glucocorticoids [16]. It is thought that these rhythms serve an overall coupling of important bodily functions which is, for example, reflected in coupling of feeding behavior and cardiomyocyte responsiveness to ingested fatty acids [8].

Coupling phenomena can be observed on the level of the entire body as a simultaneous up-regulation of cooperative hormones, such as cortisol and norepinephrine, which both rise during the early morning hours to support release of energy-rich substrates from adipose tissue and liver and both decrease at midnight kicking off nightly immune phenomena [17]. Hormones of the hypothalamic-pituitary adrenal (HPA) axis and the sympathetic nervous system (SNS) are coupled in healthy subjects but are uncoupled in patients with Crohn's disease, ulcerative colitis and systemic lupus erythematosus $[18,19]$. Circadian rhythms of cortisol can be altered in patients with RA $[20,21]$. We recently reported that coupling phenomena are important to suppress proinflammatory cytokines in primary synovial cells of patients with RA [22].

It can be hypothesized that coupling of molecular clocks that guide endogenous cellular rhythms on the peripheral cellular level play an important role in inflammation. Molecular clocks coordinate timely and functionally coupled and uncoupled cellular phenomena. Alterations of this coordination by deletion of important molecular clocks aggravate experimental arthritis as recently demonstrated for the first time in mice [23]. There is a regular cross-talk of molecular clocks and TNF in fibroblasts [23]. However, rhythms of molecular clocks have never been investigated in primary material of RA and OA patients.

This study was initiated to examine the presence of molecular clocks in primary tissue of OA and RA patients. We hypothesized that density of cells positive for molecular clocks can change during the day in these patients in a rhythmic fashion. We further hypothesized that typical daily rhythms of molecular clocks can be demonstrated in the primary fibroblast of OA and RA patients and that proinflammatory cytokines, such as IL$1 \beta$ and TNF, influence the presence and rhythm of molecular clocks.

\section{Materials and methods}

\section{Patients and control subjects}

Synovial tissue was obtained from RA and OA patients during knee replacement surgery as described earlier [24]. Control synovial tissue samples were obtained from patients with joint trauma during routine arthroscopy or open joint surgery for diagnostic and therapeutic procedures. All patients were informed of the purpose of the study and gave written consent. The study was approved by the Ethics Committee of the University of Regensburg. Characteristics of patients are given in Table 1.

\section{Immunofluorescence of synovial tissue}

The tissue preparation for histological studies was performed as previously described [24]. Cryosections (5 $\mu \mathrm{m})$ of at least three different formaldehyde-fixed synovial tissue samples from each patient/control were used. We used primary antibodies against the clock proteins BMAL-1 (1:100, polyclonal, rabbit versus human, Dianova, Hamburg, Germany), CLOCK (1:100, polyclonal, rabbit versus human, Calbiochem, Darmstadt, Germany), Period 1 (1:100, polyclonal, rabbit versus human, Millipore, Eschborn, Germany), Period 2 (1:100, polyclonal, rabbit versus human, Biozol, Eching, Germany). The secondary antibody was coupled to the fluorescent dye Alexa Fluor 546 (polyclonal, goat versus rabbit, Invitrogen, Karlsruhe, Germany). Non-specific binding sites were blocked with phosphate-buffered saline containing $10 \%$ fetal bovine serum, $10 \%$ bovine serum albumin, and $10 \%$ normal chicken serum or $10 \%$ normal goat serum for 45 minutes at room temperature. The samples were then incubated with the respective primary antibody for 3 hours at room temperature, washed and then incubated with specific secondary antibody for 90 minutes. After 4'-6-diamidino-2-phenylindole (DAPI; Roche, Mannheim, Germany) staining, slides were covered with fluorescence mounting medium (DAKO, Hamburg, Germany) and stored at $4^{\circ} \mathrm{C}$ until microscopy (performed within four days). Control staining was carried out with the secondary antibody alone or using unspecific rabbit serum instead of the primary antibody. Control staining always yielded a negative result.

\section{Synovial fibroblasts}

Mixed synoviocytes were isolated from synovial tissue as described before [24]. The cells were cultured over three to six passages yielding a homogenous cell population of synovial fibroblasts. In an earlier study [25], it was demonstrated that only after seven to eight passages more than $10 \%$ of the genes were differentially expressed. Thus, passage 6 was used as the upper limit. The same study also demonstrated that doubling rate 
Table 1 Characteristics of patients

\begin{tabular}{lcc}
\hline & Osteoarthritis & Rheumatoid arthritis \\
\hline number & 17 & 17 \\
age $(\mathrm{yr})$ & $68.8 \pm 1.6$ & $62.1 \pm 3.0$ \\
sex $(\mathrm{f} / \mathrm{m})$ & $14 / 3$ & $13 / 4$ \\
C-reactive protein (mg/l) & $9.4 \pm 4.1$ & $40.1 \pm 14.6^{*}$ \\
erythrocyte sedimentation rate (mm) & $12.4 \pm 2.6$ & $41.5 \pm 9.2^{*}$ \\
medication & & 88.0 \\
$\quad$ prednisolone (\%) & N.A. & $4.3 \pm 0.5$ \\
daily prednisolone (mg/d) & N.A. & 35.3 \\
methotrexate (\%) & N.A. & 5.9 \\
anti-TNF therapy (\%) & N.A. & 29.4 \\
leflunomide (\%) & N.A. & 5.9 \\
cyclosporin A (\%) & 41.2 & 35.3 \\
peripherally acting opioidergic drugs (\%) & 70.6 & 64.7 \\
Non-steroidal antiinflammatory drugs (\%) & \\
\hline
\end{tabular}

${ }^{*} P<0.05$ for the comparison vs. osteoarthritis. Abbreviations: N.A., not applicable.

Data are given as means \pm SEM, percentages in parentheses, and ranges in brackets

was constant for up to five passages and decreased after passages 6 to 8 [25]. With this information in mind, we focused on passages 3 to 6 , which was necessary due to the enormous amount of cells needed.

Preliminary experiments did not show a difference in molecular clock mRNA in synovial fibroblasts of passage 3 to 6 . Per well, 150,000 cells were cultured in culture medium (RPMI 1640, Sigma, Steinheim, Germany) containing $10 \%$ fetal bovine serum, $1 \%$ penicillin/streptomycin and $0.1 \%$ amphotericin B for 24 hours. Then, cells were starved for 24 hours in medium without fetal bovine serum in order to synchronize cellular rhythms as previously reported [26]. To start daily clock rhythms, cells received a serum shock ( $10 \%$ fetal bovine serum) in culture medium described above. At time $\mathrm{t}=0$, cells were treated without additional cytokines (control) or with IL-1 $\beta$ or TNF. Starting at $t=0$, cells were harvested every 2 hours for a period of 72 hours (this is a high time resolution in these types of experiments). Harvested cells were washed and stored in RNA later solution (Sigma, Steinheim, Germany) at $4^{\circ} \mathrm{C}$ and then at $-30^{\circ} \mathrm{C}$ until RNA isolation.

\section{MH7A synovial fibroblast cell line}

Some of the experiments were repeated with the MH7A synovial fibroblast cell line. This cell line was derived from immortalized synovial fibroblasts of a patient with RA using the SV40 T antigen [27]. MH7A were purchased from Riken, Japan, with informed consent of Central Research Laboratories, Kissei Pharmaceutical Co., Ltd., Nagano, Japan. Similar as mentioned for primary synovial fibroblasts, synchronization was established by serum shock. Cells were incubated at indicated concentrations of IL-1 $\beta$ and TNF. RNA isolation was performed as described.

\section{RNA isolation and quantitative PCR}

Since most studies on molecular clocks studied mRNA and because protein determination with Western blot was extremely time-consuming (preliminary studies), we used quantitative PCR to detect levels of molecular clock mRNA. RNA was isolated according to the manufacturer's instructions (Nucleo Spin RNA II Kit, Macherey Nagel, Düren, Germany). cDNA was converted from total RNA (RevertAid First Strand cDNA Synthesis Kit; Fermentas, St. Leon-Roth, Germany). For quantitative PCR (qPCR), $1 \mu \mathrm{l}$ of cDNA preparation, 1 $\mu \mathrm{l}$ of specific primer (100 pmol/ $\mu \mathrm{l}$; Eurofins MWG Operon, Ebersberg, Germany) and Brilliant II SYBR Green qPCR Master Mix (Agilent Technologies, Waldbronn, Germany) were applied in a total volume of 10 $\mu \mathrm{l}$. The PCR reaction was evaluated by melting curve analysis according to the manufacturer's instructions (Thermal Cycler 7900 HAT, Applied Biosystems, Darmstadt, Germany). Each quantitative PCR was performed in triplicate.

The following primers were used: BMAL-1 forward ATCAGACGATGAATTGAAACAC, BMAL-1 reverse TCATTCTGGCTGTAGTTGAGGA; CLOCK forward ACCСТTCCTCAACACCAAC, CLOCK reverse GACTGGGAATTTATGGACTGAC; Period 1 forward AGTTCCATTGCCTACAGCC, Period 1 reverse GAAGTGCTGTCATGAGTTCC; Period 2 forward GCATTTCATTAAGTGCGTCC, Period 2 reverse GCTTCTCTCTGTCCTCCTTC; Per3 forward GTTGTCGCCATCGTTTTTGCC, Per3 reverse 
GCTTTGTGCCTCCCACTTTTCC; Cryptochrome 1 forward GGATTGATGCCATCATGACAC, Cryptochrome 1 reverse CCTTCATTCCTTCTTCCCAAC; Cryptochrome 2 forward GCGCTGCGTTTACATTCTC, Cryptochrome 2 reverse CTTGTGTCCAAATCTTCCAGAG; Rev-erb $\alpha$ forward CCCTTCTTCCTCATCTTCCTC, Rev-erba reverse GATGTTGCTGGTGCTCTTG.

Furthermore, $\mathrm{Cdc} 2$ was detected in order to estimate the interrelation to the cell cycle because this factor is detrimental for cell cycle progression [28]. The following primers were used for Cdc2: forward ACTGGCTGATTTTGGCCTTGC, reverse AGTTGAGTAACGAGCTGACCCC. The housekeeper $18 \mathrm{~s}$ was used as control using the following primers: forward CGGCTACCACATCCAAGGAA, reverse GCTGGAATTACCGCGGCTGC. Each gene was normalized to the house keeper mRNA of 18s. The ratio of the mRNA of a specific gene divided by the mRNA of $18 \mathrm{~s}$ at $\mathrm{t}=0$ was defined as 1.00 and ratios of every following time point were calculated in relation to $\mathrm{t}=0$.

\section{Statistical analyses}

Medians of groups were compared by Mann-Whitney U test and Box Plots were demonstrated to respect the non-normal distribution of data (Sigma Plot 11.0, Systat Software, Inc., Erkrath, Germany). For time series analysis, cubic regression was used for the interrelation of time of day and density of cells positive for molecular clocks in synovial tissue (Sigma Plot). In addition, autocorrelation analyses were used to identify a possible period of the rhythm (PASW Statistics, 18.0, IBM SPSS via IBM Germany, Ehningen, Germany). We did not use a sine or cosine wave fitting model because it was unclear whether or not oscillations really exist. Trigonometric wave fitting always yields a rhythm and, thus, it is not useful to apply this technique in a situation where the presence of oscillation is not really known. Elapsed time between serum shock synchronization and first peak of molecular clock mRNA curves was determined by inspection of mRNA curves in every individual. The significance level was $P<0.05$.

\section{Results}

\section{Clock proteins in synovial tissue}

The presence of molecular clocks is a prerequisite for endogenous cellular rhythms. This prompted us to study protein abundance in primary material of patients with OA, RA and trauma controls. Immunofluorescence demonstrated ubiquitous cellular distribution of BMAL1, CLOCK, Period 1 and Period 2 proteins in patients with RA and OA (Figure 1). Without variation, all cells demonstrated these four clock proteins. In addition, specimens of trauma controls similarly demonstrated the four molecular clocks (data not shown).

In order to study a possible difference between $\mathrm{OA}$ and RA material, cellular density of synovial cells positive for molecular clocks was investigated. While synovial density of positive cells for CLOCK and Period 2 were similar between disease groups, density of BMAL1-positive cells was higher in RA compared to OA (Figure 2A). For Period 1-positive cells, a similar trend existed (Figure 2A). This indicates that RA synovial tissue provides an environment for increased molecular clock levels.

Since BMAL-1 and Period 1 undulate during the day, we hypothesized that this oscillation can be visible when taking patient material at different operation time points during the day. We had access to material taken between 8:00 am and 4:00 pm of a large number of patients with RA and OA as well as trauma controls. Although one would have expected a difference between morning and afternoon, no statistically significant variation of synovial density of positive cells was observed in these patient groups (Figure 2B).

In preliminary experiments, we evaluated the use of Western blots for further protein analyses of molecular clocks (data not shown). However, due to the time series with 36 time points of cell removal and lack of adequate amounts of primary cells, this technique was abandoned.

\section{Molecular clock mRNA in synovial fibroblasts}

Typically, quantitative PCR is used to study undulation of molecular clock mRNA over three days [15], which was also employed in the present study. After serum shock synchronization, synovial fibroblasts start with a huge rise of molecular clock mRNA as demonstrated in Figure 3. The rise of mRNA is immediate for Period 1 and Period 2 and a little delayed for BMAL- 1 in both $\mathrm{OA}$ and RA patients (Figure 3 ). Using the median of mRNA of all patients in a disease group at a single time point, we were able to demonstrate oscillation curves with a total of maximal four peaks (Figure 3, yellow areas). However, time series analysis with autocorrelation did not reveal a regular pattern to determine a period of oscillation in OA and RA patients (data not shown). In other words, oscillation is masked by a low signal-to-noise ratio in OA and RA patients.

Only in fibroblasts of healthy subjects did we find a regular rhythm for BMAL-1 and Period 1 as demonstrated by autocorrelation analyses (Additional file 1, Figure S1A). These analyses revealed a period of 24 hours for both molecular clocks (Additional file 1, Figure S1A; time between red coefficients outside the confidence limits). 


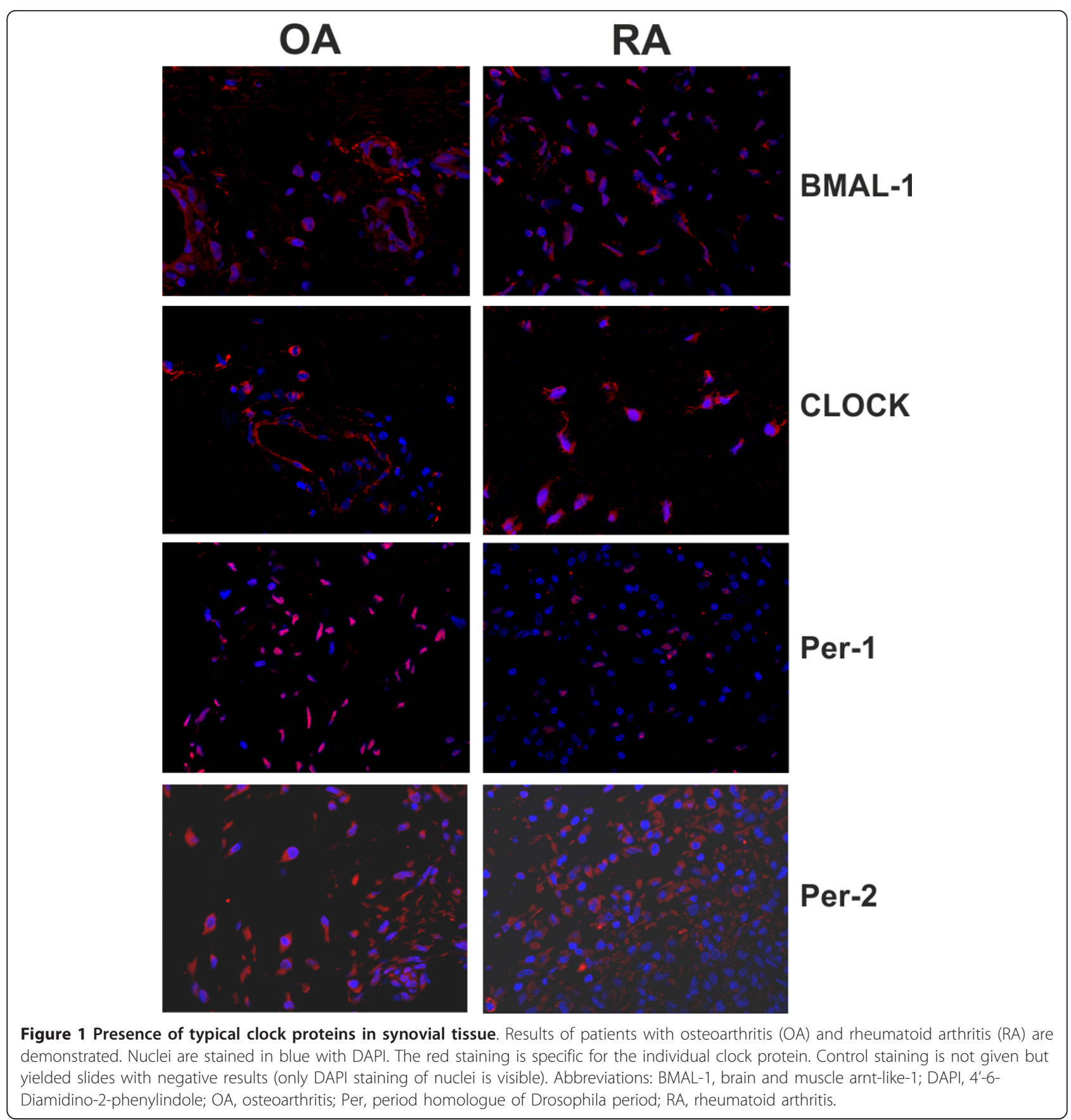

Influence of IL-1 $\beta$ and TNF on molecular clock mRNA in synovial fibroblasts

Since time series did not reveal molecular clock mRNA oscillation in OA and RA patients, we used the average of all 36 time points of every patient for further analyses. IL-1 $\beta$ and TNF are abundant proinflammatory cytokines found in patients with OA and RA. Thus, these two cytokines were studied in order to investigate the influence on molecular clock mRNA. While IL-1 $\beta$ had no influence on average mRNA of BMAL-1,
CLOCK, Period 1 and Period 2 in OA synovial fibroblasts (Figure 4A), TNF inhibited mRNA of CLOCK, Period 1 and Period 2 (Figure 4A). This is demonstrated in the oscillation curve of Period 1 mRNA (compare green line of control conditions with brown line in Figure $4 \mathrm{~B}$, right panel). There are no influences on the BMAL-1 mRNA oscillation curve (Figure 4B, left panel). Similar to OA synovial fibroblasts, fibroblasts of healthy controls show a slight reduction of average CLOCK mRNA by TNF (Additional file 1, Figure S1B). 


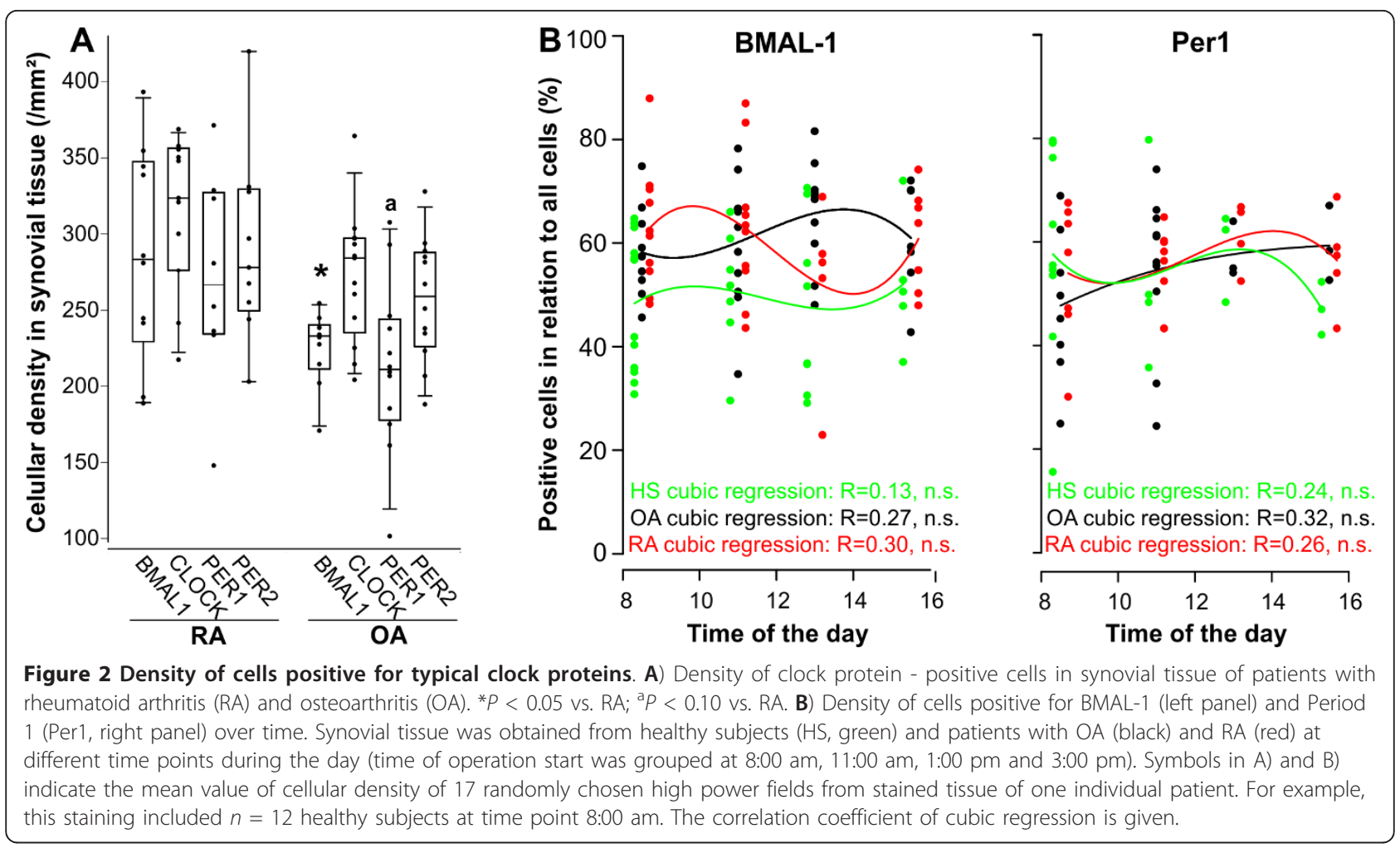

In contrast to OA synovial fibroblasts, both cytokines stimulated average mRNA of RA synovial fibroblasts (Figure 5A), which is exemplified by BMAL-1 and Period 1 mRNA oscillation curves (Figure $5 \mathrm{~B}$ ). The different protein levels demonstrated in Figure 2A supports that increased mRNA levels translates into increased protein levels.

In order to intensify these investigations, the RA synovial fibroblast cell line MH7A was used (a large number of cells was obtained from these non-primary cells). Both, IL- $1 \beta$ and TNF dose-dependently increased mRNA of Period 1 and Period 2 (Figure 6A). This was similar for CLOCK mRNA but was not statistically significant for BMAL-1 mRNA (Additional file 2, Figure S2).

In order to investigate a possible cell cycle-dependent abundance of molecular clocks, the ubiquitous cell cycle progression factor $\mathrm{Cdc} 2$ was investigated. The oscillation curve of Cdc2 mRNA had one peak at approximately 30 hours after synchronization indicating one concerted proliferation event (Additional file 3, Figure S3A), which was largely different from the immediate peak of molecular clocks (compare Figure 3). Thus, there seems to be no direct interrelation between cell cycle and molecular clocks because no parallel or anti-parallel rise or fall of mRNA was observed. Interestingly, IL-1 $\beta$ and TNF increased Cdc2 mRNA in RA but not in OA or control subjects (Additional file 3, Figure S3B). In the direct comparison of RA and OA oscillation of $\mathrm{Cdc} 2$ mRNA, the peak was little delayed in RA compared to OA (Additional file 4, Figure S4, black letters).

\section{Influence of IL-1 $\beta$ and TNF on molecular clock mRNA oscillation characteristics}

Proinflammatory cytokines might influence oscillation characteristics of molecular clocks. As mentioned above, the period of the oscillation cannot be studied due to the rapid loss of rhythmicity (see all curves in Figure 3). Thus, elapsed time from start of synchronization to the first peak of the undulation curve was scrutinized. Both, IL-1 $\beta$ and TNF delayed the first peak of BMAL-1 mRNA oscillation in RA synovial fibroblasts, which did not reach the significance level in OA synovial fibroblasts (Figure 6B). IL-1 $\beta$ and TNF did not change oscillation characteristics of other molecular clocks investigated (Additional file 4, Figure S4).

Obviously, there exist four different groups of molecular clocks as determined by the elapsed time from start to first peak (Additional file 4, Figure S4). One group has the peak between 0 and $6 \mathrm{~h}$ (blue), one group between 8 and $14 \mathrm{~h}$ (pink), another group between 14 and $17 \mathrm{~h}$ (red), and a fourth group between 18 and $19 \mathrm{~h}$ (green). Molecular clocks in these different groups reflect the different partners of the intracellular molecular clock network (Additional file 5, Figure S5). However, conditions in RA and OA synovial fibroblasts 


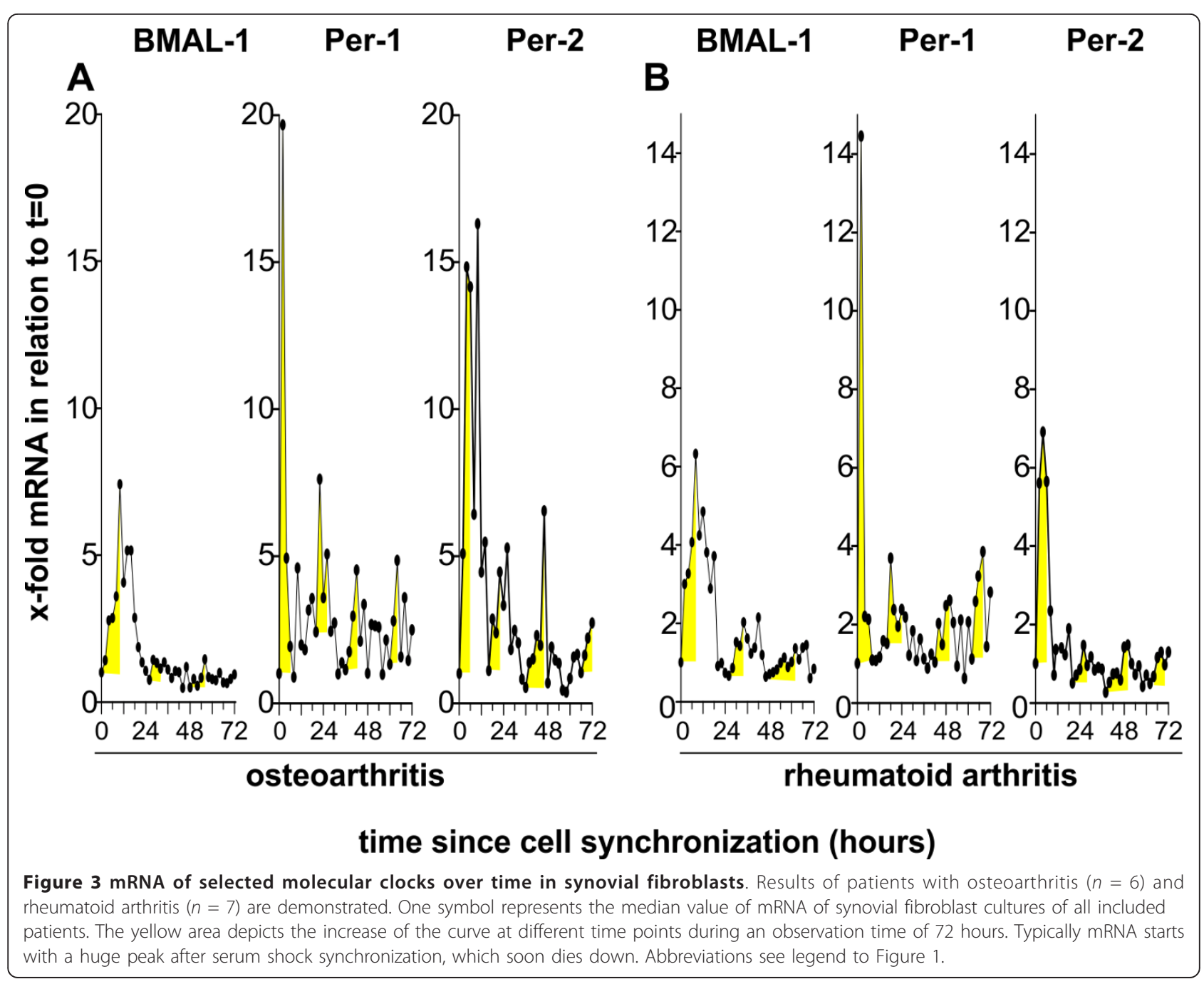

prevent one or two full oscillation cycles, which are visible in healthy fibroblasts (Additional file 1, Figure S1A).

\section{Discussion}

Molecular clocks play an important role in coordinating circadian rhythms in the body and intracellular circadian networks in peripheral cells. It is thought that the coordinated network establishes coupling and uncoupling of pathways to support cellular function in parallel and anti-parallel fashion. To our knowledge, molecular clock proteins have not been investigated in primary synovial material of patients with OA and RA but similarly not in other rheumatic diseases.

There are three reports that linked molecular clocks to rheumatology. In mouse chondrocytes, CLOCK, Period 1 and Period 2 were found to exhibit biological rhythms after serum shock [29]. The authors found CLOCK upregulated after mechanical stress which identifies CLOCK as a possible mechanosensitive gene [29].
Another report demonstrated that melatonin inhibited Cryptochrome 1 in a mouse model of experimental arthritis [30]. However, no functional tests were performed to understand the link between melatonin, cryptochrome 1 and proinflammatory mechanisms [30].

In a third study, the authors investigated mice with collagen type II-induced arthritis using synovial and spleen cells [23]. They found marked upregulation of Period 2 independent of the light dark cycle in arthritic animals. This is somewhat similar to the upregulation observed in RA patients compared to OA (Figure 2A). In addition, they found that daily rhythm of Period $1 / 2$ mRNA shifted six hours back and that of Bmal-1 mRNA remained constantly low indicating dampened rhythm [23]. They further demonstrated that mice deficient in Cryptochrome 1 and Cryptochrome 2 demonstrated arthritis aggravation, which might be due to upregulation of TNF [23]. They concluded that the lack of Cryptochrome gene function abrogates normal 

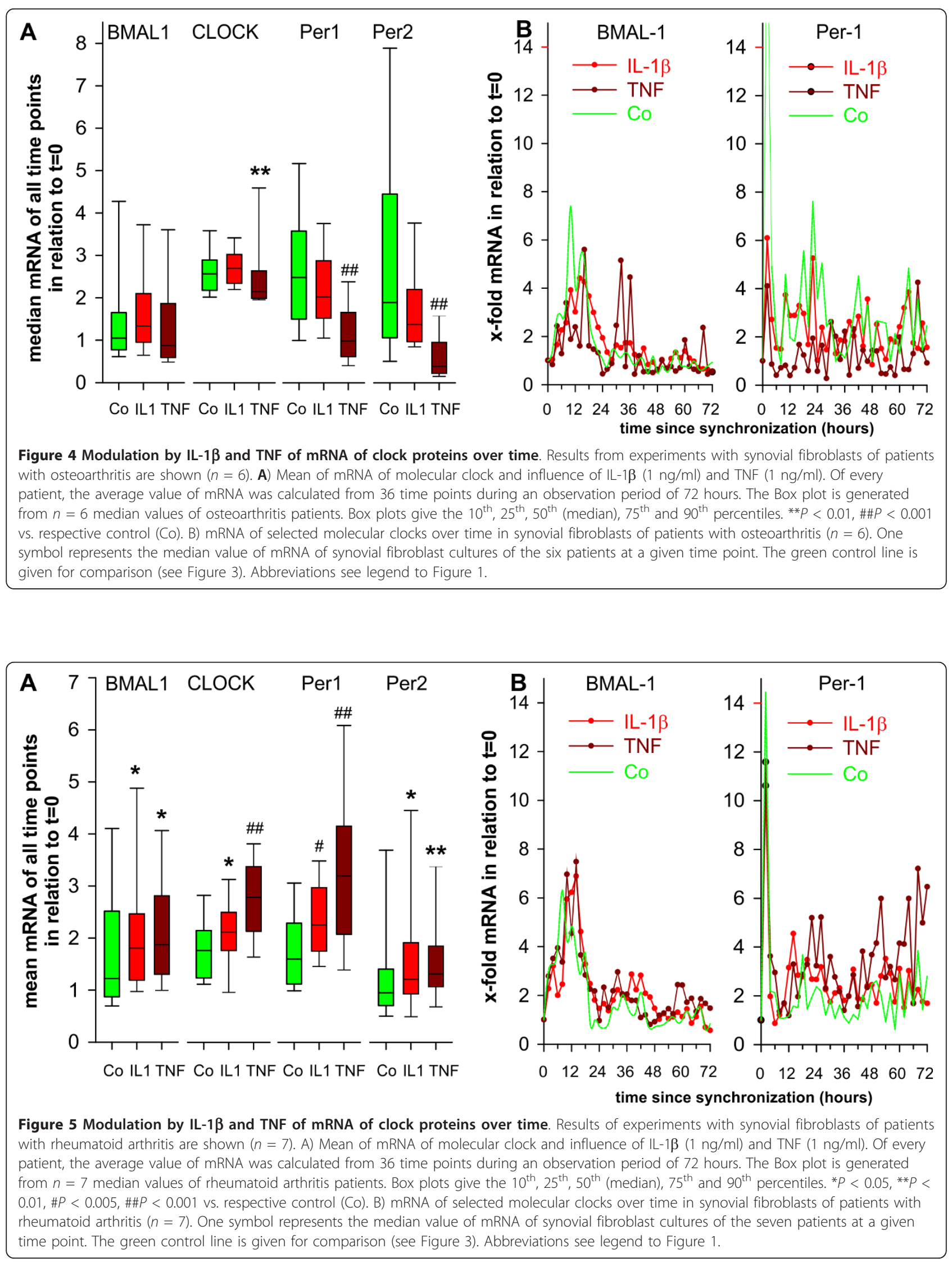


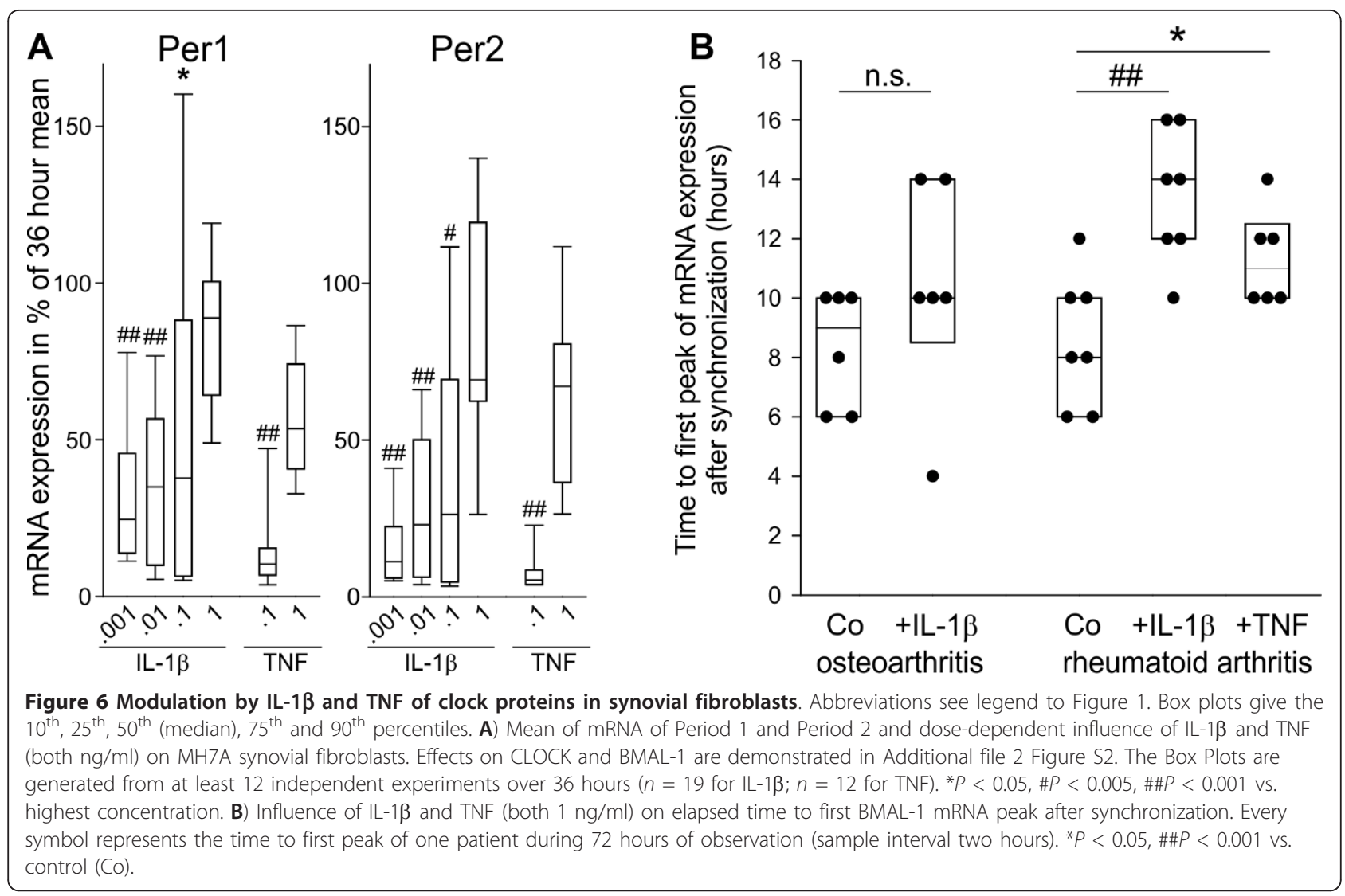

biological clock function and aggravates pathological changes in arthritis.

Our report adds more information on human subjects with OA and RA. All clock proteins are ubiquitously present in synovial cells of these patients and in trauma controls (all cells are positive). It seems that density of molecular clock-positive cells was higher in RA compared to OA, which was significant for BMAL-1. Since we have not corrected for overall cellular density, this difference might depend on increased cellular infiltration in RA compared to OA though density is relatively similar in the chronic phase of both diseases. In addition, a possible undulation of density of molecular clock-positive cells did not exist in synovial tissue. This might depend on several mechanisms, such as heterogeneous chronotypes of investigated patients (two chronotypes are known: lark and owl), different medication in the various patients that might influence molecular clock levels, short observation period from 8:00 am to 4:00 $\mathrm{pm}$, and low numbers of investigated patients (type II error). Since several studies demonstrated that inflammation disturbs molecular clock oscillation in different cell types in vivo and in vitro [31-36], it might well be that typical oscillations are abrogated in inflamed tissue in OA and RA.
A closer investigation of molecular clock mRNA demonstrated that synovial fibroblasts of OA and RA patients are capable of starting the typical oscillation. However, a long-standing rhythm was not established because the signal rapidly died down. Time series analysis did not demonstrate regularity in OA and RA but in healthy fibroblasts. This can depend on the contact to the proinflammatory environment to which these cells have been adapted prior to serum shock synchronization in OA and RA [31-36].

When comparing the hardly visible oscillation in these synovial fibroblasts of OA and RA patients, fibroblasts of normal rats demonstrate excellent rhythmic oscillation [15]. From this first study in rat fibroblasts, this cell type was one of the typical peripheral cell types to study daily rhythms of the intracellular molecular clock network [37-40]. This is also true for normal human fibroblasts of the skin [40], and we also found a rhythm in fibroblasts of healthy individuals. Thus, one would have expected similar rhythms in OA and RA fibroblasts. The question appears whether or not proinflammatory factors can influence molecular clock mRNA.

Our study demonstrated that proinflammatory cytokines decreased or tended to decrease mRNA of molecular clocks in OA synovial fibroblasts. This was 
opposite in RA synovial fibroblast which might also explain the higher density of molecular clock - positive cells in RA synovial tissue. In these experiments, we used a dose of $1 \mathrm{ng} / \mathrm{ml}$ of IL-1 $\beta$ or TNF. Although this is a typical cytokine concentration to stimulate cells in vitro, it does not give us a dose-response effect and it is difficult to simply translate it to a situation in vivo. Nevertheless, these concentrations appear in the proximity of cytokine-producing cells. In order to study the subject more carefully, we applied different doses in the MH7A RA synovial fibroblast cell line. Here a clear dose-response was observable.

In addition, IL- $1 \beta$ and TNF both changed the time point of the first BMAL-1 mRNA peak by induction of a delay of approximately three to six hours. Similar shifts of molecular clock peaks have been demonstrated in a model of experimental arthritis [23], which indicates that inflammation can directly interfere with rhythmicity of cells. This is supported by a TNF-induced inhibition of Period 1 to 3 in NIH 3T3 fibroblasts and in mice which depends on a direct influence of BMAL-1 and CLOCK binding to the E-box [36]. In addition, expression of molecular clock genes was markedly inhibited in peripheral blood leukocytes in surgical ICU patients [41].

In further time series analyses, according to the first peak of mRNA rhythm, four different groups of molecular clocks were identified. Period 1, Period 2, Period 3, cryptochrome 1 and cryptochrome 2 (blue in Additional files 4 and 5, Figures S4 and S5) demonstrated the first peak immediately after the serum shock. BMAL-1 and CLOCK demonstrated an intermediate pattern with a peak at 8 to 17 hours (pink and red in Additional files 4 and 5, Figures S4 and S5). Furthermore, the peak of Rev-Erbo mRNA appeared late between 18 and 19 hours (green in Additional files 4 and 5, Figures S4 and S5). This sequential increase of mRNA peaks is indicative of a first successful attempt to start oscillation in these OA and RA synovial fibroblasts. However, this phenomenon is impermanent, leading to rapid destruction of the rhythm.

\section{Conclusions}

These experiments with primary synovial tissue and fibroblasts did not demonstrate the expected oscillation of molecular clock protein or mRNA. Since proinflammatory cytokines can change the level of mRNA and time interval to peak mRNA, the proinflammatory environment most probably destroys the regular rhythm. Since synovial fibroblasts were derived from chronically inflamed tissue, molecular clock alterations are most probably programmed for a longer period of time. Disruption of coupled intracellular pathways might be a proinflammatory event.

\section{Additional material}

Additional file 1: Autocorrelation of clock factors and modulation by IL-1 $\beta$ and TNF of mRNA expression of clock proteins over time in synovial fibroblasts from healthy subjects. A) Autocorrelation coefficient of selected clock factors. Autocorrelation is used to show a period of oscillation. mRNA expression levels of BMAL-1 and Per1 at 36 separate time points over 72 hours were used to generate

autocorrelation diagrams. Every bar represents an autocorrelation coefficient generated by moving the data with the given lag number. The red lines in the graph give the $95 \%$ confidence interval of the correlation coefficients. Only red coefficients outside the red lines are significant. B) Mean of mRNA expression of clock factor and influence of $\mathrm{IL}-1 \beta(1 \mathrm{ng} / \mathrm{ml})$ and TNF $(1 \mathrm{ng} / \mathrm{ml})$. Of every person, the average value of mRNA expression was calculated from 36 time points during an observation period of 72 hours. The Box plot is generated from $n=4$ median values of healthy subjects. Box plots give the $10^{\text {th }}, 25^{\text {th }}, 50^{\text {th }}$ (median), $75^{\text {th }}$ and $90^{\text {th }}$ percentiles. \#\#P $<0.001$ vs. respective control (Co). Abbreviations see legend to Figure 1.

Additional file 2: Modulation by IL-1 $\beta$ and TNF of clock proteins in synovial fibroblasts. Abbreviations see legend to Figure 1. Mean of mRNA expression of BMAL-1 and CLOCK and dose-dependent influence of IL-1 $\beta$ and TNF (both $\mathrm{ng} / \mathrm{ml}$ ) on MH7A synovial fibroblasts. The Box Plots are generated from at least 12 independent experiments over 36 hours ( $n=19$ for IL-1b; $n=12$ for TNF). Box plots give the $10^{\text {th }}, 25^{\text {th }}, 50^{\text {th }}$ (median), $75^{\text {th }}$ and $90^{\text {th }}$ percentiles. ${ }^{*} P<0.05,{ }^{* *} P<0.01, \# P<0.005$ vs. highest concentration.

Additional file 3: Modulation by IL-1 $\beta$ and TNF of mRNA expression of the cell cycle factor $\mathrm{Cdc} 2$ over time in synovial fibroblasts of patients with rheumatoid arthritis (RA, $n=7)$, osteoarthritis (OA, $n=$ 6), and healthy subjects ( $H S, \boldsymbol{n}=\mathbf{4})$. Abbreviations see legend to Figure 1 . A) mRNA expression of Cdc2 over time in fibroblasts of patients with RA and $\mathrm{OA}$, and $\mathrm{HS}$. The lines are generated using the median value of mRNA expression of synovial fibroblast cultures at 36 time points during 72 hours. B) Average of mRNA expression of clock factor and influence of IL-1 1 (1 ng/ $\mathrm{ml})$ and TNF (1 ng/ml). Of every subject, the average value of mRNA expression was calculated from 36 time points during an observation period of 72 hours. The Box plot is generated from values of patients with $\mathrm{RA}$ and $\mathrm{OA}$, and HS. Box plots give the $10^{\text {th }}, 25^{\text {th }}, 50^{\text {th }}$ (median), $75^{\text {th }}$ and $90^{\text {th }}$ percentiles. ${ }^{*} P<0.05$, \#\#P<0.001 vs. respective control $(\mathrm{Co})$.

Additional file 4: First peak after cell synchronization of individual clock factor mRNAs in OA $(n=6)$ and RA $(n=7)$ with and without additional $1 \mathrm{ng} \mathrm{IL-1 \beta /ml}$. Different colors indicate co-regulated factors according to Additional file 5, Figure S5. ${ }^{*} P<0.05$ vs. OA Cdc $2+\mathrm{IL}-1 \beta$; \#P $<0.005$ vs. OA Cdc2; \#\#P<0.001 vs. RA BMAl-1 without IL-1 $\beta$; $\S C d c 2$ is not a clock factor but a cell cycle progression factor which indicates the cell cyle progression and, thus, proliferation. Abbreviations: BMAL-1, brain and muscle ARNT-like 1; Crypt, cryptochrome; OA, osteoarthritis; Per, period homologue of Drosophila period; RA, rheumatoid arthritis; reverba, V-erbA-related protein 1-related; sync, synchronization.

Additional file 5: Regulation of the circadian rhythm of clock proteins. The interwoven pathways are given: $1^{\mathrm{s}} \mathrm{t}$ pathway: CLOCK $(C)$, BMAL-1(B), Period 1 to 3 (Per1, 2, 3), and Cryptochrome $1+2($ Cry 1,2$) ; 2^{\text {nd }}$ pathway: Rev-Erba, BMAL-1. CLOCK and BMAL 1 dimerize and bind to Eboxes in the promotor region of Period (Per) genes, cryptochrome (Cry) genes, Rev-Erbo, and BMAL-1 activating their transcription. The corresponding proteins accumulate in the cytoplasm, translocate to the nucleus, and inhibit binding of CLOCK and BMAL-1 to the E-Boxes. This inhibition leads to a down-regulation of transcription of these genes. A very similar loop exists with respect to Rev-Erbo and BMAL-1 regulation. The degradation process via ubiquitination and SUMOylation leads to the know 24 hour cycle.

\section{Abbreviations}

DAPI: 4'-6-diamidino-2-phenylindole; HPA: hypothalamic-pituitary-adrenal; IL: interleukin; OA: osteoarthritis; RA: rheumatoid arthritis; SF: synovial fibroblasts; SNS: sympathetic nervous system; TNF: tumor necrosis factor. 


\section{Acknowledgements}

This study was supported by the institution and partly by the Deutsche Forschungsgemeinschaft (DFG FOR696).

\section{Authors' contributions}

SH generated the data and draft figures, and drafted parts of the paper. RHS generated data and the final figures, and drafted the paper. Both authors gave final approval of the manuscript.

\section{Competing interests}

The authors declare that they have no competing interests.

Received: 19 March 2012 Revised: 20 April 2012

Accepted: 23 May 2012 Published: 23 May 2012

\section{References}

1. Straub RH, Cutolo M: Circadian rhythms in rheumatoid arthritis: implications for pathophysiology and therapeutic management. Arthritis Rheum 2007, 56:399-408.

2. Arvidson NG, Gudbjornsson B, Elfman L, Ryden AC, Totterman $T H$, Hallgren R: Circadian rhythm of serum interleukin-6 in rheumatoid arthritis. Ann Rheum Dis 1994, 53:521-524.

3. Cutolo M, Seriolo B, Craviotto C, Pizzorni C, Sulli A: Circadian rhythms in RA. Ann Rheum Dis 2003, 62:593-596.

4. Clarke L, Jessop D, Hunt L, Straub R, Perry M, Kirwan J: Alleviation of morning joint stiffness by low-dose prednisone in rheumatoid arthritis is associated with circadian changes in IL-6 and cortisol. Int J Clin Rheumatol 2011, 6:241-249.

5. Arvidson NG, Gudbjornsson B, Larsson A, Hallgren R: The timing of glucocorticoid administration in rheumatoid arthritis. Ann Rheum Dis 1997, 56:27-31.

6. Buttgereit F, Doering G, Schaeffler A, Witte $S$, Sierakowski S, Gromnica-thle E, Jeka S, Krueger K, Szechinski J, Alten R: Efficacy of modified-release versus standard prednisone to reduce duration of morning stiffness of the joints in rheumatoid arthritis (CAPRA-1): a double-blind, randomised controlled trial. Lancet 2008, 371:205-214.

7. Moore RY, Eichler VB: Loss of a circadian adrenal corticosterone rhythm following suprachiasmatic lesions in the rat. Brain Res 1972, 42:201-206.

8. Durgan DJ, Trexler NA, Egbejimi O, McElfresh TA, Suk HY, Petterson LE, Shaw CA, Hardin PE, Bray MS, Chandler MP, Chow CW, Young ME: The circadian clock within the cardiomyocyte is essential for responsiveness of the heart to fatty acids. J Biol Chem 2006, 281:24254-24269.

9. Terazono H, Mutoh T, Yamaguchi S, Kobayashi M, Akiyama M, Udo R, Ohdo S, Okamura H, Shibata S: Adrenergic regulation of clock gene expression in mouse liver. Proc Natl Acad Sci USA 2003, 100:6795-6800.

10. Boivin DB, James FO, WU A, Cho-Park PF, Xiong H, Sun ZS: Circadian clock genes oscillate in human peripheral blood mononuclear cells. Blood 2003, 102:4143-4145.

11. Arjona A, Sarkar DK: Circadian oscillations of clock genes, cytolytic factors, and cytokines in rat NK cells. J Immunol 2005, 174:7618-7624.

12. Bollinger T, Leutz A, Leliavski A, Skrum L, Kovac J, Bonacina L, Benedict C, Lange T, Westermann J, Oster H, Solbach W: Circadian clocks in mouse and human CD4+ T cells. PLoS One 2011, 6:e29801.

13. Logan RW, Arjona A, Sarkar DK: Role of sympathetic nervous system in the entrainment of circadian natural-killer cell function. Brain Behav Immun 2011, 25:101-109.

14. Groos GA, Hendriks J: Regularly firing neurones in the rat suprachiasmatic nucleus. Experientia 1979, 35:1597-1598.

15. Balsalobre A, Damiola F, Schibler U: A serum shock induces circadian gene expression in mammalian tissue culture cells. Cell 1998, 93:929-937.

16. Balsalobre A, Brown SA, Marcacci L, Tronche F, Kellendonk C, Reichardt HM, Schutz G, Schibler U: Resetting of circadian time in peripheral tissues by glucocorticoid signaling. Science 2000, 289:2344-2347.

17. Straub RH, Cutolo M, Buttgereit F, Pongratz G: Energy regulation and neuroendocrine-immune control in chronic inflammatory diseases. $J$ Intern Med 2010, 267:543-560

18. Straub RH, Herfarth H, Falk W, Andus T, Schölmerich J: Uncoupling of the sympathetic nervous system and the hypothalamic-pituitary-adrenal axis in inflammatory bowel disease? J Neuroimmunol 2002, 126:116-125.

19. Härle P, Straub RH, Wiest R, Maier A, Schölmerich J, Atzeni F, Carrabba M, Cutolo M, Sarzi-Puttini P: Increase of sympathetic outflow measured by
NPY and decrease of the hypothalamic-pituitary-adrenal axis tone in patients with SLE and RA - another example of uncoupling of response systems. Ann Rheum Dis 2005, 65:51-56.

20. Neeck G, Federlin K, Graef V, Rusch D, Schmidt KL: Adrenal secretion of cortisol in patients with rheumatoid arthritis. J Rheumatol 1990, 17:24-29.

21. Dekkers JC, Geenen R, Godaert GL, van Doornen L, Bijlsma JW: Diurnal rhythm of salivary cortisol levels in patients with recent-onset rheumatoid arthritis. Arthritis Rheum 2000, 43:465-467.

22. Straub RH, Günzler C, Miller LE, Cutolo M, Schölmerich J, Schill S: Antiinflammatory cooperativity of corticosteroids and norepinephrine in rheumatoid arthritis synovial tissue in vivo and in vitro. FASEB J 2002, 16:993-1000.

23. Hashiramoto A, Yamane T, Tsumiyama K, Yoshida K, Komai K, Yamada H, Yamazaki F, Doi M, Okamura H, Shiozawa S: Mammalian clock gene Cryptochrome regulates arthritis via proinflammatory cytokine TNFalpha. J Immunol 2010, 184:1560-1565.

24. Miller LE, Jüsten HP, Schölmerich J, Straub RH: The loss of sympathetic nerve fibers in the synovial tissue of patients with rheumatoid arthritis is accompanied by increased norepinephrine release from synovial macrophages. FASEB J 2000, 14:2097-2107.

25. Neumann E, Riepl B, Knedla A, Lefevre S, Tarner IH, Grifka J, Steinmeyer J, Scholmerich J, Gay S, Muller-Ladner U: Cell culture and passaging alters gene expression pattern and proliferation rate in rheumatoid arthritis synovial fibroblasts. Arthritis Res Ther 2010, 12:R83.

26. Balsalobre A, Marcacci L, Schibler U: Multiple signaling pathways elicit circadian gene expression in cultured Rat-1 fibroblasts. Curr Biol 2000, 10:1291-1294

27. Miyazawa K, Mori A, Okudaira H: Establishment and characterization of a novel human rheumatoid fibroblast-like synoviocyte line, MH7A, immortalized with SV40 T antigen. J Biochem 1998, 124:1153-1162.

28. Hu X, Moscinski LC: Cdc2: a monopotent or pluripotent CDK? Cell Prolif 2011, 44:205-211.

29. Kanbe $K$, Inoue $K$, Xiang C, Chen Q: Identification of clock as a mechanosensitive gene by large-scale DNA microarray analysis: downregulation in osteoarthritic cartilage. Mod Rheumatol 2006, 16:131-136.

30. Bang J, Chang HW, Jung HR, Cho CH, Hur JA, Lee Sl, Choi TH, Kim SH, Ha E: Melatonin attenuates clock gene Cryptochrome1, which may aggravates mouse anti-type II collagen antibody-induced arthritis. Rheumatol Int 2012, 32:379-385.

31. Lundkvist GB, Sellix MT, Nygard M, Davis E, Straume M, Kristensson K, Block GD: Clock gene expression during chronic inflammation induced by infection with Trypanosoma brucei brucei in rats. J Biol Rhythms 2010, 25:92-102.

32. Haimovich B, Calvano J, Haimovich AD, Calvano SE, Coyle SM, Lowry SF: In vivo endotoxin synchronizes and suppresses clock gene expression in human peripheral blood leukocytes. Crit Care Med 2010, 38:751-758.

33. Yamamura Y, Yano I, Kudo T, Shibata S: Time-dependent inhibitory effect of lipopolysaccharide injection on Per1 and Per2 gene expression in the mouse heart and liver. Chronobiol Int 2010, 27:213-232.

34. Petrzilka S, Taraborrelli C, Cavadini G, Fontana A, Birchler T: Clock gene modulation by TNF-alpha depends on calcium and p38 MAP kinase signaling. J Biol Rhythms 2009, 24:283-294

35. Okada K, Yano M, Doki Y, Azama T, Iwanaga H, Miki H, Nakayama M, Miyata H, Takiguchi S, Fujiwara Y, Yasuda T, Ishida N, Monden M: Injection of LPS causes transient suppression of biological clock genes in rats. J Surg Res 2008, 145:5-12.

36. Cavadini G, Petrzilka S, Kohler P, Jud C, Tobler I, Birchler T, Fontana A: TNFalpha suppresses the expression of clock genes by interfering with $\mathrm{E}$ box-mediated transcription. Proc Natl Acad Sci USA 2007, 104:12843-12848.

37. Nishii K, Yamanaka I, Yasuda M, Kiyohara YB, Kitayama Y, Kondo T, Yagita K: Rhythmic post-transcriptional regulation of the circadian clock protein mPER2 in mammalian cells: a real-time analysis. Neurosci Lett 2006, 401:44-48.

38. Izumo M, Johnson $\mathrm{CH}$, Yamazaki S: Circadian gene expression in mammalian fibroblasts revealed by real-time luminescence reporting: temperature compensation and damping. Proc Natl Acad Sci USA 2003, 100:16089-16094.

39. Yagita K, Tamanini F, van Der Horst GT, Okamura H: Molecular mechanisms of the biological clock in cultured fibroblasts. Science 2001, 292:278-281. 
40. Zanello SB, Jackson DM, Holick MF: Expression of the circadian clock genes clock and period1 in human skin. J Invest Dermatol 2000, 115:757-760.

41. Haimovich B, Reddell MT, Calvano JE, Calvano SE, Macor MA, Coyle SM, Lowry SF: A novel model of common Toll-like receptor 4- and injuryinduced transcriptional themes in human leukocytes. Crit Care 2010, 14. R177.

doi:10.1186/ar3852

Cite this article as: Haas and Straub: Disruption of rhythms of molecular clocks in primary synovial fibroblasts of patients with osteoarthritis and rheumatoid arthritis, role of IL-1 $\beta /$ TNF. Arthritis Research \& Therapy 2012 14:R122.

Submit your next manuscript to BioMed Central and take full advantage of:

- Convenient online submission

- Thorough peer review

- No space constraints or color figure charges

- Immediate publication on acceptance

- Inclusion in PubMed, CAS, Scopus and Google Scholar

- Research which is freely available for redistribution

Submit your manuscript at www.biomedcentral.com/submit 